\title{
EVALUATION OF A HYDROGEL BASED POINT-OF-CARE DIAGNOSTIC APPROACH FOR NEISSERIA GONORRHOEAE IDENTIFICATION
}

\section{Sumudu R Perera ${ }^{1,2}$, Ali Taheri², Nurul H Khan², Stephanie Stefura³, Pauline Skiba³, Jason P Acker ${ }^{3}$, Anthony Kusalik ${ }^{4}$, and Jo-Anne R Dillon ${ }^{1,2}$}

\begin{abstract}
${ }^{1}$ Department of Microbiology and Immunology; ${ }^{2}$ Vaccine and Infectious Disease Organization - International Vaccine Centre, University of Saskatchewan, Canada; ${ }^{3}$ Aquila Diagnostic Systems Inc., Edmonton AB; ${ }^{4}$ Department of Computer Science, University of Saskatchewan, Saskatoon SK, Canada
\end{abstract}

\section{BACKGROUND}

In resource limited settings, appropriate laboratory infrastructure for the diagnosis of Neisseria gonorrhoeae $(\mathrm{Ng})$ infections is often absent ${ }^{1}$. The use of reliable and affordable point-of-care tests (POCTs) could provide accurate diagnosis of Ng. A hydrogelbased RT-PCR platform (Aquila Diagnostic Systems Inc.) was previously shown to be successful for diagnosing pathogens such as Herpes simplex virus and Plasmodium falciparum from clinical specimens such as blood and genital swabs ${ }^{2,3}$. The platform is compact and does not require highly trained personnel. As a potential POCT to diagnose $\mathrm{Ng}$ infections, we evaluated this hydrogel-based platform to identify Ng DNA isolated from cultures using novel, Ng specific primers.

\section{METHODS}

11 pairs of $N$. gonorrhoeae specific primers developed and assessed in silico and in vitro

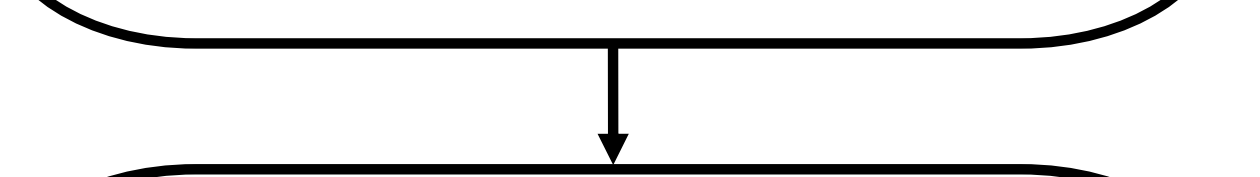

Primers evaluated using varying DNA concentrations from $135 \mathrm{~N}$. gonorrhoeae and 50 control isolates

Primer pairs 3, 17-1, and 21-5 evaluated with the hydrogel method. Desiccated gels containing primers and SYBR dye supplied by Aquila Diagnostics Systems Inc

DNA from 50 N. gonorrhoeae and 10 control isolates was added to the hydrogels immediately before RT-PCR amplification. Results compared to non-hydrogel based RT-PCR methods

\section{REFERENCES}

1. Dillon JR, Parti RP, Thakur SD. 2015. Culture 35(1):1-8.

2. Manage DP, Lauzon J, Atrazhev A, Morrissey YC, Edwards AL, Stickel AJ, Crabtree HJ, Pabbaraju K, Zahariadis G, Yanow SK, Pilarski LM. 2012. Lab Chip 12:1664-1671.

3. Taylor BJ, Howell A, Martin KA, Manage DP, Gordy W, Campbell SD, Lam S, Jin A, Polley SD, Samuel RA, Atrazhev A, Stickel AJ, Birungi J, Mbonye AK, Palarski LM, Acker JP Yanow SK. 2014. Malaria Journal 13:179.

\section{ACKNOWLEDGEMENTS}

NSERC
CRSNG

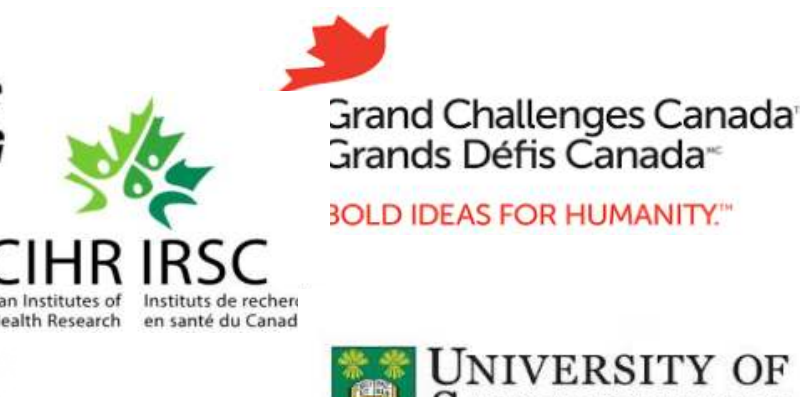

\section{RESULTS}

TABLE 1. Evaluation of Eleven Primer Pairs Using N. gonorrhoeae, non-N. gonorrhoeae and non-Nesseria Species

\begin{tabular}{|c|c|c|c|c|c|c|c|c|c|c|c|c|}
\hline \multirow{2}{*}{$\begin{array}{c}\text { Bacterial } \\
\text { Species }\end{array}$} & \multirow{2}{*}{$\begin{array}{c}\text { \# } \\
\text { Isolates }\end{array}$} & \multicolumn{11}{|c|}{ Amplifications with Primer Pairs } \\
\hline & & 3 & $8-4$ & 16 & 17-1 & $17-2$ & 21-5 & 31-2 & 2 & 31-3 & 8-3 & 13 \\
\hline N. gonorrhoeae & 130 & 130 & 130 & 130 & 130 & 130 & 130 & 130 & 129 & 102 & 130 & 130 \\
\hline N. flava & 2 & 0 & 0 & 0 & 0 & 0 & 0 & 0 & 0 & 0 & 1 & 2 \\
\hline N. subflava & 2 & 0 & 0 & 0 & 0 & 0 & 0 & 0 & 0 & 0 & 0 & 1 \\
\hline N. elongata & 2 & 0 & 0 & 0 & 0 & 0 & 0 & 0 & 0 & 0 & 0 & 0 \\
\hline N. mucosa & 3 & 0 & 0 & 0 & 0 & 0 & 0 & 0 & 0 & 0 & 0 & 1 \\
\hline N. lactamica & 4 & 0 & 0 & 0 & 0 & 0 & 0 & 0 & 0 & 0 & 2 & 2 \\
\hline N. perflava/sicca & 5 & 0 & 0 & 0 & 0 & 0 & 0 & 0 & 0 & 0 & 0 & 3 \\
\hline N. flavescens & 2 & 0 & 0 & 0 & 0 & 0 & 0 & 0 & 0 & 0 & 0 & 1 \\
\hline N. polysacchareae & 4 & 0 & 0 & 0 & 0 & 0 & 0 & 0 & 0 & 0 & 1 & 2 \\
\hline Neisseria species & 6 & 0 & 0 & 0 & 0 & 0 & 0 & 0 & 0 & 0 & 0 & 0 \\
\hline $\begin{array}{l}\text { Non-Neisseria } \\
\text { species }\end{array}$ & 10 & 0 & 0 & 0 & 0 & 0 & 0 & 0 & 0 & 0 & 0 & 0 \\
\hline
\end{tabular}

- Seven primer pairs $(3,8-4,16,17-1,17-2,21-5,31-2)$ had $100 \%$ sensitivity and specificity (Table 1)

- The hydrogel method was $100 \%$ sensitive and specific with $100 \mathrm{ng} / \mu \mathrm{L}$ Ng DNA (Table 2)

- While having a positive $\mathrm{Ng}$ diagnosis by melt curve analysis, most samples contained negative threshold cycle (Ct) values (Table 2)

- A final concentration of $4 X$ SYBR dye resulted in favourable $\mathrm{Ct}$ values (Table 2)

TABLE 2. Evaluation of Hydrogel Methods Using Primer Pairs 3, 17-1 and 21-5

\begin{tabular}{|c|c|c|c|c|c|c|}
\hline \multirow{2}{*}{$\begin{array}{l}\text { Primer } \\
\text { Pair }\end{array}$} & \multirow[t]{2}{*}{ Method } & \multirow{2}{*}{ 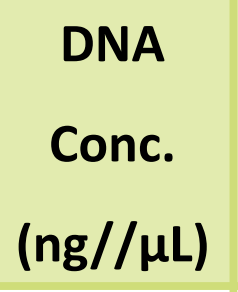 } & \multicolumn{2}{|c|}{ \# Ng Isolates } & \multicolumn{2}{|c|}{ Based on Tm } \\
\hline & & & $\begin{array}{l}\text { Identified by } \\
\text { Tm value }\end{array}$ & $\begin{array}{l}\text { Positive } \\
\text { Ct values }\end{array}$ & $\begin{array}{c}\text { Sensitivity } \\
\text { (\%) }\end{array}$ & $\begin{array}{c}\text { Specificity } \\
\text { (\%) }\end{array}$ \\
\hline 3 & Hydrogel & 50 & 44 & 0 & 88 & 100 \\
\hline 3 & Hydrogel & 70 & 46 & 33 & 92 & 100 \\
\hline 3 & Hydrogel & 100 & 50 & 0 & 100 & 100 \\
\hline 3 & $4 X \mathrm{SYBR}^{\mathrm{b}}$ & 100 & 50 & 50 & 100 & 100 \\
\hline 3 & RT-PCR control & 70 & 50 & 50 & 100 & $67^{c}$ \\
\hline $17-1$ & Hydrogel & 50 & 50 & 0 & 100 & 100 \\
\hline $17-1$ & Hydrogel & 70 & 50 & 0 & 100 & 100 \\
\hline $17-1$ & Hydrogel & 100 & 50 & 0 & 100 & 100 \\
\hline $17-1$ & RT-PCR control & 70 & 50 & 50 & 100 & 100 \\
\hline $21-5$ & Hydrogel & 50 & 47 & 0 & 94 & 100 \\
\hline $21-5$ & Hydrogel & 70 & 50 & 0 & 100 & 100 \\
\hline $21-5$ & Hydrogel & 100 & 50 & 0 & 100 & 100 \\
\hline $21-5$ & RT-PCR control & 70 & 48 & 49 & 96 & 100 \\
\hline
\end{tabular}

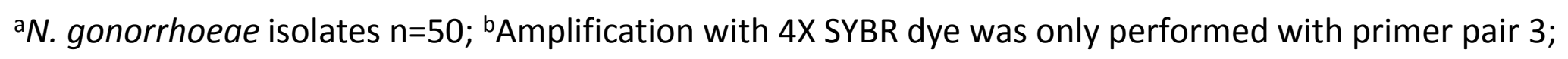
'One Escherichia coli isolate was identified as N. gonorrhoeae positive

\section{CONCLUSIONS}

- 3 novel primer pairs successfully identify Ng DNA isolated from cultures in the hydrogel platform

- These primers represent new diagnostics

- The hydrogel platform will be tested using clinical specimens (i.e. urines, self-collected vaginal or rectal swabs)

- The hydrogel platform has potential as a POCT for Ng diagnosis 